the coupling matrix element, and the total reorganization energy is expressed in terms of the solvational $\left(\lambda_{s}\right)$ and vibrational $\left(\lambda_{v}\right)$ components. The $\Delta G^{\circ}$ value used in equation 4 was obtained from the assigned relative electron transfer exothermicity for compounds 1-7 ( $\Delta G^{\circ}$ rel, Table 2$)$ and an added shift correction

$$
\Delta G^{\circ}=\Delta G_{\text {rel }}^{\circ}+\Delta G_{\text {shift }}
$$

The $\Delta G_{\text {shift }}$ term contains coulomb and ion-pairing corrections and any other systematic errors in the assignment of the electron transfer exothermicity. The effect of the $\Delta G_{\text {shift }}$ correction is to shift the origin of the relative $\Delta G^{\circ}$ scale. The present kinetic analysis assumes no repopulation of the porphyrin excited singlet via the charge-separated state which may be close in energy (for example, compound 1). Work in progress will assess the validity of this assumption.

Using a value of $\Delta G_{\text {shift }}=0.48 \mathrm{eV}$, equation (4) gives a curve of the form shown in Fig. 2 for benzene with the following parameters: $T_{\mathrm{ab}}=8 \mathrm{~cm}^{-1}, \lambda_{\mathrm{v}}=0.3 \mathrm{eV}, \lambda_{\mathrm{s}}=0.3 \mathrm{eV}$, and $h \nu=$ $1,500 \mathrm{~cm}^{-1}$. The choice for $h \nu$ and $\lambda_{\mathrm{v}}$ are reasonable for the reduction of a benzoquinone and the previously obtained value of $T_{\mathrm{ab}}$. The parameters obtained from the data are in accord with estimates of $h \nu=1,500 \mathrm{~cm}^{-1}$ and $\lambda_{\mathrm{v}}=0.3 \mathrm{eV}$ calculated from an average force constant for the $\mathrm{CO}$ stretches of a quinone $\mathrm{e}^{24,25}$ and a semiquinone (approximated by a phenolic $\mathrm{CO}$ stretch), bond length changes ${ }^{26,27}$ between $\mathrm{C}=\mathrm{O}$ and $\mathrm{C}-\mathrm{O}$ $(\sim 0.2 \AA)$, and the extent of spin delocalization onto the semiquinone ring obtained from electron paramagnetic resonance studies $^{28}$.

In summary, the classical and semi-classical expressions qualitatively describes the rising side of the curve. The fluctuations observed in the insensitive region may be fine structure present in the electron transfer rates for this series that is not adequately described by these theories and may require alternative theoretical interpretations. The $\Delta G$ range would have to be extended to more negative values to see whether or not 'inverted behaviour' is obtained. This series examines exothermicity effects on photon-induced electron transfer rates uncomplicated by major electronic perturbations, changes in outer sphere reorganization energies, or poorly-defined donor-acceptor distances, and should provide critical experimental measurements for further theoretical refinements.

A.H.Z. J.J.H. and P.B.D. thank the NSF for support. We thank Professor R. Marcus for helpful discussions, Professor F. Anson's group for assistance with the electrochemistry, and J. M. Warman for critical reading of the manuscript.

Received 6 October 1986; accepted 9 March 1987

1. Deisenhofer, J., Epp, O., Miki, K., Huber, R. \& Michel, H. Nature 318, 618-624 (1985) 2. Deisenhofer, J., Epp, O., Miki, K., Huber, R. \& Michel, H. J. molec, Biol 180, 385-398 (1984) Leland, B. A. et al. J. phys. Chem. 89, 5571-5573 (1985).

4. Joran, A. D., Leland, B. A., Geller, G. G., Hopfield, J. J. \& Dervan, P. B. J. Am. chem. Soc 106, 6090-6092 (1984).

5. Warman, J. M. et at. Nature 320, 615-616. (1986).

6. Miller, J. R., Calcaterra, L. T. \& Close, G. L. J. Am chem. Soc, 106, 3047-3049 (1984)

7. Wasielewski, M. R Ni, L. \& Close, G. L. J. Am. chem. Soc. 106, 3047-3049 (1984). 1080-1082 (1985).

8. Irvine, M. P., Harrison, R. J., Beddard, G. S., Leighton, P. \& Sanders, J. K. M. Chem. Phys. 104, 315-324 (1986).

9. Rehm, D. \& Weller, A. Israel J. Chem. 8, 259-271 (1970).

10. Pasman, P., Mes, G. F., Koper, N. W. \& Verhoeven, J. W. J. Am. chem. Soc. 107, 5839-5843 (1985).

11. Schmidt, J. A., Siemiarczuk, A. Weedon, A. C. \& Bolton, J. R. J. Am. chem. Soc, 107 $6112-6116(1985)$

2. Harris, D., Johnson, A. W. \& Gaete-Holmes, R. Bioorg. Chem. 9, 63-70 (1980)

13. Lambert, W. R., Felker, P. M. \& Zewail, A. H. J. chem. Phys. 81, 2217-2232 (1984); Felker, P. M. \& Zewail, A. H. J. chem. Phys. 82, 2975-2993 (1985)

14. Marcus, R. A. J. chem. Phys. 24, 966-978 (1956)

15. Hopfield, J. Proc. natn. Acad. Sci. U.S.A. 71, 3640-3644 (1974)

16. Marcus, R. A. \& Sutin, N. Biochem. biophys. Acta 811, 265-322 (1985)

17. Gunner, M. R. Robertson, P. E. \& Dutton, P. L. J. phys. Chem. (in the press)

18. Jortner, J. J. chem. Phys 64, 4860-4867 (1976).

19. Jortner, J. J. Am. chem. Soc. 102, 6676-6686 (1980)

20. Buhks, E. \& Jortner, J. FEBS Lett. 109, 117-120 (1980)

21. Hopfield, J. J. in Protein Structure: Molecular and Electronic Reactivity (eds Austin, R. H. et al.) (Springer, New York, in the press).

22. Ulstrup, J. \& Jortner, J. J. chem. Phys. 63, 4358-4368 (1975)

23. Marcus, R. A. Discuss. Faraday Soc. 74, $7(1982)$

24. Anno, T. \& Sadô, A. Bull. chem. Soc. Japan 31, 734-739 (1958)

25. Baudet, M. J., Berthier, G. \& Pullman, B. J. chim. Phys. 54, 282-284 (1957)

26. S. M. Swingle, J. Am. chem. Soc. 76, 1409 (1954).

27. Bratoz, M. S. Besnainou, M. S. J. chim. Phys, 56, 555-562 (1959).

28. Higasi, K., Baba, H. \& Rembaum, A. Quantum Organic Chemistry 242-246 (Interscience. New York, 1965).

\section{Oscillating selection on Darwin's finches}

\author{
H. Lisle Gibbs* \& Peter R. Grant $\dagger$ \\ * Department of Biology, The University of Michigan, Ann Arbor, \\ Michigan 48109-1048, USA \\ $\dagger$ Department of Biology, Princeton University, Princeton, \\ New Jersey 08544, USA
}

An important goal in the study of evolution is to determine the occurrence, causes and possible micro-evolutionary consequences of selection in natural populations ${ }^{1-3}$. Darwin's finches (Geospizinae) are suitable organisms for investigation because their morphological traits are highly heritable ${ }^{4}$, and they live in a climatically variable environment (Galápagos Islands) ${ }^{5,6}$. It has been suggested that selection fluctuates in direction and intensity, favouring different morphological optima in different years', because strong annual variation in rainfall causes changes in food supply composition ${ }^{7,8}$. This suggestion has been supported in part by studies of the medium ground finch, Geospiza fortis, on the island of Daphne Major, which have shown that large adult size is favoured under drought conditions, when the overall food supply is low and large hard seeds are disproportionately abundant ${ }^{\mathbf{8 , 9}}$. Here we document a reversal in the direction of selection following the opposite climatic extreme, and demonstrate the connection between oscillating selection and fluctuations in food supply.

From December 1982 until July 1983, exceptionally heavy and prolonged rain fell on Daphne Major ${ }^{10,11}$, in association with the most severe El Niño event (an oceanic disturbance) of the century ${ }^{12}$. A total of $1,359 \mathrm{~mm}$ of rain was recorded, ten times the previously recorded maximum of $137 \mathrm{~mm}$ in 1978 . Birds bred continuously for eight months ${ }^{10,11}$, instead of the usual one to three months, and by the time the rains ceased both food level (seeds) and bird density were exceptionally high. We examined the survival of individually ringed and measured birds over the next two years when rainfall was low $(53 \mathrm{~mm}$, 1984 ) to very low ( $4 \mathrm{~mm}, 1985$ ). During this time seed biomass steadily declined but was nevertheless higher than in the dry years of 1977 and 1982.

We measured directional selection on adults by comparing the sizes of survivors and non-survivors. Results are given in Table 1 under two headings. Selection gradients $(\beta)$ represent the direct effects of selection on each trait and are measured as the partial regression coefficients of relative fitness (survival) on each trait ${ }^{11}$. Selection differentials $(s)$ measure the combined direct effects and indirect effects of selection caused by phenotypic correlations between traits, and are calculated as the difference in the mean value of the trait before and after selection, here measured in standard deviation units ${ }^{1}$.

Small adults survived better than large ones in the two years following the exceptionally wet El Niño year (Table 1, Fig. 1); selection differentials for all measured traits were negative and often significant. These are in marked contrast to selection on all traits in the opposite direction under the contrasting conditions of drought and low overall food supply (Fig. 1).

Selection was consistent over sexes and cohorts. For example, all selection differentials for males and females were negative, although not all were significantly different from zero. Males, the larger sex, were apparently subject to stronger selection than females. Selection differentials for overall body size (principal 
Table 1 Standardized selection differentials $(s)$ and gradients $(\beta)$ for adult $G$. fortis from 1984 to the beginning of 1986

\begin{tabular}{|c|c|c|c|c|c|c|}
\hline \multirow[b]{3}{*}{ Character } & \multicolumn{6}{|c|}{ Periods of selection } \\
\hline & \multicolumn{2}{|c|}{1984} & \multicolumn{2}{|c|}{1985} & \multicolumn{2}{|c|}{ 1984-85 combined } \\
\hline & $\beta$ & $s$ & $\beta$ & $s$ & $\beta$ & $s$ \\
\hline Weight & $-0.12 \pm 0.07$ & $-0.12^{* *}$ & $-0.03 \pm 0.08$ & -0.08 & $-0.09 \pm 0.10$ & $-0.18^{* *}$ \\
\hline Wing & $-0.07 \pm 0.06$ & $-0.09^{*}$ & $0.15 \pm 0.07^{*}$ & 0.03 & $0.11 \pm 0.08$ & -0.06 \\
\hline Tarsus & $0.03 \pm 0.06$ & -0.06 & $-0.06 \pm 0.06$ & -0.09 & $-0.09 \pm 0.07$ & $-0.17^{* *}$ \\
\hline Bill length & $0.10 \pm 0.06$ & -0.03 & $-0.10 \pm 0.07$ & -0.05 & $0.08 \pm 0.09$ & -0.09 \\
\hline Bill depth & $0.13 \pm 0.09$ & $-0.08^{*}$ & $-0.02 \pm 0.11$ & $-0.10^{*}$ & $0.03 \pm 0.13$ & $-0.18^{* *}$ \\
\hline Bill width & $-0.21 \pm 0.09^{*}$ & $-0.12^{* *}$ & $-0.15 \pm 0.10$ & $-0.11^{* *}$ & $-0.29 \pm 0.12^{*}$ & $-0.21^{* * *}$ \\
\hline PC I & & $-0.12^{* *}$ & & $-0.10^{* *}$ & & $-0.21^{* * *}$ \\
\hline PC II & & 0.03 & & 0.00 & & 0.03 \\
\hline$N$ & $314(0.61)$ & $320-391$ & $316(0.56)$ & $318-341$ & $489(0.36)$ & $496-537$ \\
\hline$r^{2}$ & $0.06^{*}$ & - & $0.05^{*}$ & - & $0.05^{* *}$ & - \\
\hline
\end{tabular}

Values of $\beta$ are shown \pm s.e.m. Before each analysis data were $\log _{e}$-transformed and standardized to have zero mean and unit variance. Principal component (PC) scores were extracted from a correlation matrix calculated from all individuals for which measurements of all six univariate traits were available. PC I is interpreted as a measure of overall body size because all characters load positively on it, whereas PC II is interpreted as a shape index in terms of bill size relative to tarsus length ${ }^{15} . N$ is the number of birds alive at the beginning of the period, and varies according to the number of measurements taken. The proportion surviving is given in parentheses. The 1984-85 combined sample includes birds born in 1984 . Significance of selection differentials was assessed by $t$-tests comparing survivors with those who disappeared $\left({ }^{*} P \leqslant 0.05 ;{ }^{* *} P \leqslant 0.01 ;{ }^{* * *} P \leqslant 0.001\right)$.

component I, PCI in Table 1) were almost twice as large for males $(-0.41, P<0.001)$ as for females $(-0.22, P<0.05)$.

Significant $\beta$ values identify the targets of direct selection among the set of intercorrelated morphological traits ${ }^{4}$ subject to analysis. No single trait, with the possible exception of bill width, was an obvious target of selection (Table 1). In one year selection weakly favoured increased wing length, but no net selection occurred because of a positive correlation with overall size which was selected in the opposite direction. These results differ from those during droughts and conditions of low food supply, when individual targets and directions of selection could be clearly identified (weight and bill depth selected to increase, bill width selected to decrease ${ }^{9}$ ). Thus we interpret the strong differentials and weak gradients to indicate selection on overall body size, as manifested by highly significant negative selection differentials for PCI scores (Table 1).

Large adult size is favoured when food is scarce because the supply of small and soft seeds is depleted first, and only those birds with large bills can crack open the remaining large and hard seeds ${ }^{3,8,9,13}$. In contrast, small adult size is favoured in years following very wet conditions, possibly because the food

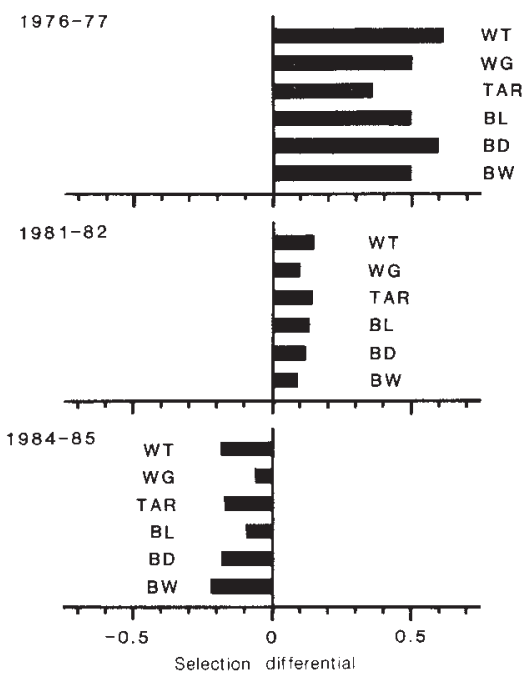

Fig. 1 Selection differentials for traits of adult $G$. fortis during two years of drought and low food supply, 1976-77 and 1981-82 (ref. 9), and during the years that followed the El Niño event of 1982-83. Traits measured are shown as follows. WT, weight; WG, wing length; TAR, tarsus size; BL, bill length; BD, bill depth; BW, bill width. supply is dominated by small soft seeds. In 1984 and 1985, the proportion of total seed biomass made up by small soft seeds was $21 \%$ to $80 \%{ }^{11}$, which is two to ten times greater than the previous maximum ( $8 \%$ in May 1978) following a normal wet year. Despite an initially large standing crop of seeds, finch mortality was high and correlated with size, possibly because large birds had difficulty finding enough large seeds. As has been found in other years ${ }^{8,13-15}$, finches seen feeding on large seeds were significantly larger in all traits except bill length, and in PCI scores, than those feeding solely on small seeds ( $t$-tests, $P \leqslant 0.05)$ in 1984 and 1985 ( $N=108-124$ birds). Thus morphological contraints on foraging behaviour may underlie the fluctuating selection on body size under the contrasting feeding conditions induced by droughts and El Niño events.

In contrast to adults, juveniles were not subjected to directional selection on body size or bill size during the first six to nine months following their birth in 1983 and 1984. Juveniles were not present in 1985 because no successful breeding occurred in this year. Small size is favoured among juveniles when small seeds are scarce following a breeding season ${ }^{16}$.

The chief implication of the results of this long-term study is that natural populations subject to the effects of rare climatic perturbations are not at a fixed equilibrium state demographically, phenotypically, or genetically. Selection in opposite directions on the two sexes ${ }^{17-20}$, on correlated traits within a sex ${ }^{9,19}$, on different life-history stages of both sexes ${ }^{16,21}$, or on the same age and sex group in different years and generations, may result in weak overall stabilizing selection on morphological traits over a period greater than a single generation ${ }^{3,4,22}$.

We thank Philip de Maynadier, Steven Latta, Robert Podolsky, Dan Rosenberg, Jonathan Weiland and David Wiggins for assistance in the field, and James Fry, Rosemary Grant, Philip Myers, Robert Payne and Trevor Price for advice. This study was conducted with permission and support from the Dirección General de Desarrollo Forestal, Quito, the National Parks Service, Galápagos, and the Charles Darwin Research Station. It was funded by grants from the NSF. H.L.G. was supported by a Natural Sciences and Engineering Research Council of Canada Postgraduate Scholarship for part of the study.

Received 30 Janury; accepted 24 March 1987

1. Lande, R. \& Arnold, S. J. Evolution 37, 1210-1226 (1983).

2. Endler, J. A. Natural Selection in the Wild (Princeton University Press, 1986).

3. Grant, P. R. Ecology and Evolution of Darwin's Finches (Princeton University Press, 1986).

4. Boag, P. T. Evolution 37, 877-894 (1983).

5. Grant, P. R. \& Boag, P. T Auk 97, 227-244 (1980)

6. Grant, P. R. Am. Om. Un. Monogr. 36, 471-483 (1985). 
7. Grant, P. R., Grant, B. R., Smith, J. N. M., Abbott, I. J. \& Abbott, L. K. Proc. natn. Acad. Sci U.S.A. 73, 257-261 (1976).

8. Boag, P. T. \& Grant, P. R. Science 214, 82-85 (1981).

9. Price, T. D., Grant, P. R., Gibbs, H. L. \& Boag, P. T. Nature 309, 787-789 (1984).

10. Gibbs, H. L., Grant, P. R. \& Weiland, J. Auk 101, 872-874 (1984).

11. Gibbs, H. L. \& Grant, P. R. Ecology 68 (in the press).

12. Cane, M. A. Science 222, 1189-1195 (1983).

13. Price, T. D. Ecology 68 (in the press).

14. Grant, P. R. Anim. Behav. 29, 785-793 (1981)

15. Ban P. T. \& Grant, P. R. Biol J. Linn Soc. Lond 22, 243-287 (1984).

16. Price, T. D. \& Grant, P. R. Evolution 38, 483-494 (1984).

17. Fleischer, R. C. \& Johnston, R. F. Nature 298, $747-749$ (1982)

18. Price, T. D. Am. Nat. 123, 500-518 (1984)

19. Grant, B. R. Evolution 39, 523-532 (1985)

20. Monaghan, P. \& Metcalfe, P. Evolution 40, 1096-1099 (1986)

21. Schluter D. \& Smith J. N. M. Evolution 40, 221-231 (1986).

22. Grant, P. R. \& Price, T. D. Am. Zool. 21, 795-811 (1981).

\section{NMDA receptors in the visual cortex of young kittens are more effective than those of adult cats}

\section{T. Tsumoto, K. Hagihara, H. Sato \& Y. Hata}

Department of Neurophysiology, Institute of Higher Nervous Activity, Osaka University Medical School, Kitaku, Osaka, 530 Japan

Acidic amino acids, such as glutamate and aspartate, are thought to be excitatory transmitters in the cerebral neocortex and hippocampus $^{1-8}$. Receptors for these amino acids can be classified into at least three types on the basis of their agonists. Quisqualatepreferring receptors and kainate-preferring receptors are implicated in the mediation of synaptic transmission in many regions including the hippocampus ${ }^{9,10}$ and visual cortex ${ }^{11}$, whereas $N$ methyl-D-aspartate (NMDA)-preferring receptors are thought to be involved in modulating synaptic efficacy, for example in longterm potentiation, a form of synaptic plasticity in the hippocampus $^{12-14}$. In the visual cortex of the cat and monkey, it is well established that synaptic plasticity, estimated by susceptibility of binocular responsiveness of cortical neurons to monocular visual deprivation, disappears after the 'critical' period of postnatal development ${ }^{15-17}$. Here we report that during the critical period in young kittens, a selective NMDA-receptor antagonist blocks visual responses of cortical neurons much more effectively than it does in the adult cat. This suggests that NMDA receptors may be involved in establishing synaptic plasticity in the kitten visual cortex.

Nine adult cats and seven kittens, aged between 4 and 8 weeks and thus at a stage when the synaptic plasticity of the visual cortex is highest ${ }^{15,16}$, were used. Experimental procedures for preparing and maintaining the animals, visual and electrical stimulations and extracellular single unit recordings were as detailed previously ${ }^{5}$. During recordings the animals were anaesthetized with a gas mixture of $70 \% \quad \mathrm{~N}_{2} \mathrm{O}$ and $30 \% \quad \mathrm{O}_{2}$, and paralysed with gallamine triethiodide (Flaxedil). The heart rate was continuously monitored. If it was suddenly changed by noxious stimuli, $0.1-0.5 \%$ halothane was added to the gas to maintain an adequate depth of anaesthesia. Three- or fourbarrelled micropipettes for ionophoretic application of drugs contained 2-amino-5-phosphonovaleric acid (APV, $50 \mathrm{mM}, p \mathrm{H}$ 8.0), a selective NMDA antagonist ${ }^{9,10}$, and kynurenic acid (50 mM, pH 8.0), a broad-spectrum excitatory amino-acid antagonist ${ }^{5,18,19}$. In addition, the pipettes contained L-glutamate $(0.2 \mathrm{M}, p \mathrm{H} 8.0)$, NMDA (50 mM, $p \mathrm{H} 8.0)$, quisqualate $(20 \mathrm{mM}$, $p \mathrm{H} 8.0)$ and kainate $(20 \mathrm{mM}, p \mathrm{H} 8.0)$.

In adult cats, 69 cells recorded from the primary visual cortex were tested with drugs. As in a previous report ${ }^{5}$, ionophoretic application of kynuremic acid effectively suppressed visual responses in $71 \%$ of the cells tested (Fig. 1a). The application of APV, on the other hand, significantly suppressed visual responses in only $33 \%$ of the cells (Fig. $1 b$ and Table 1 ). The current intensity for APV was set either at, or 10-20 nA above, the intensity at which APV blocked completely excitations induced by the application of NMDA. Also, APV was ineffective in suppressing responses elicited by single electrical shocks applied to the dorsal lateral geniculate nucleus (LGN) in $77 \%$ of the cells tested whereas kynuremic acid blocked the responses, particularly those with latencies shorter than $2 \mathrm{~ms}$, in $84 \%$ of the cells (and see ref. 20).

In the kittens, however, APV suppressed visual responses in $71 \%$ of the cortical cells tested (Fig. $2 a$ and Table 1). Usually, APV suppressed visual responses with approximately the same intensity of current as kynurenic acid, but the suppression by APV was less complete than that by kynurenic acid. With this range of currents, APV completely blocked excitations induced by NMDA but not by quisqualate and kainate, as in the adult. In double-spike responses evoked by LGN stimulation (Fig. $2 b$ ), the initial responses were found relatively resistant to APV but the secondary spikes were highly susceptible.

A summary of the results is shown in Table 1. In the adult, the proportion of cells suppressed by APV was only $33 \%$ whereas it was $71 \%$ in the kittens. The difference in these values is statistically significant ( $\chi^{2}$-test, $\left.P<0.001\right)$. The laminar distribution of the cells in the kittens was not markedly different from that in the adult. In the 44 suppressed cells of the kittens, the mean intensity of current ( \pm s.d.) required for APV to exert its full action was $43 \pm 17 \mathrm{nA}$, which is significantly ( $t$-test, $P<$ $0.005)$ smaller than that of the adult $(65 \pm 22 \mathrm{nA}$, number of cells, $n=23$ ). Also, the minimum intensity of currents for NMDA needed to excite cells in the kittens ( $33 \pm 20 \mathrm{nA}, n=18)$
Fig. 1 Effects of an ionophoretic application of kynurenic acid and 2-amino-5-phosphonovaleric acid (APV) on visual responses of a cortical neuron recorded from an adult cat. $a$, Suppressive effects of kynurenic acid (KNYA); $b$, lack of effect of APV. Shown are peristimulus time histograms of spikes recorded extracellularly to a light slit moving back and forth over the receptive field. Direction of motion and orientation of the slit are indicated at the top. Twenty sweeps for each histogram; bin width $4 \mathrm{~ms}$. Stimulus speed was $17.2 \mathrm{deg} \mathrm{s}^{-1}$. Top row, control histograms cumulated without application of any drug; second to fourth rows, histograms cumulated during application of the drug indicated. Numbers at the right of drug name, current intensity used (nA); numbers below drug name, time after starting the ejection of each drug. Bottom row, control histograms cumulated after the end of the drug application.
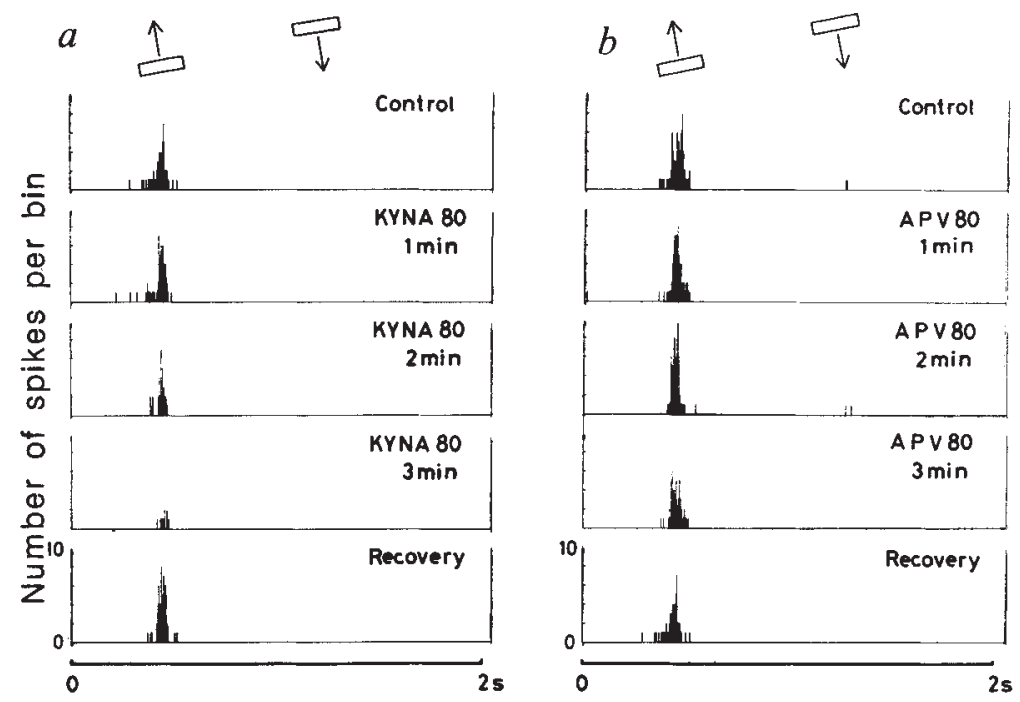